Canadian

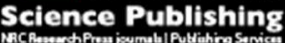

Biochemistry and Cell Biology Biochimie et biologie cellulaire

\title{
Conformational Change in Individual Enzyme Molecules
}

\begin{tabular}{|r|l|}
\hline Journal: & Biochemistry and Cell Biology \\
\hline Manuscript ID & bcb-2015-0099.R1 \\
\hline Manuscript Type: & Article \\
\hline Date Submitted by the Author: & $21-$ Sep-2015 \\
\hline Complete List of Authors: & $\begin{array}{l}\text { Crawford, Jeremie; University of Manitoba, Chemistry } \\
\text { Itzkow, Frannie; University of Winnipeg, Chemistry } \\
\text { MacLean, Joanna; University of Winnipeg, Chemistry } \\
\text { Craig, Douglas; University of Winnipeg }\end{array}$ \\
\hline Keyword: & $\begin{array}{l}\beta-\text { galactosidase, electrophoretic heterogeneity, catalytic heterogeneity, } \\
\text { conformational change, capillary electrophoresis }\end{array}$ \\
\hline
\end{tabular}

SCHOLARONE ${ }^{m}$

Manuscripts 


\section{Conformational Change in Individual Enzyme Molecules}

Jeremie J Crawford ${ }^{1}$, Frannie Itzkow ${ }^{2}$, Joanna MacLean ${ }^{2}$ \& Douglas B Craig ${ }^{2,3}$

${ }^{1}$ Chemistry Department, University of Manitoba, Winnipeg, Manitoba, Canada

${ }^{2}$ Chemistry Department, University of Winnipeg, Winnipeg, Manitoba, Canada

${ }^{3}$ Corresponding author

Key words: $\beta$-galactosidase, electrophoretic heterogeneity, catalytic heterogeneity, heat shock proteins, heating, conformational change, capillary electrophoresis 


\begin{abstract}
Single $\beta$-galactosidase molecule assays were performed using a capillary electrophoresis based protocol employing post-column laser-induced fluorescence detection. In a first set of experiments, the distribution of single $\beta$-galactosidase molecule catalytic rates and electrophoretic mobilities were determined from lysates of E. coli strains containing deletions for different heat shock proteins and grown under normal and heat shock conditions. There was no clear observed pattern of effect of heat shock protein expression on these distributions. In a second set of experiments, individual enzyme molecule catalytic rates were determined at $21^{\circ} \mathrm{C}$ before and after 2 sequential brief periods of incubation at 50,28 and $10^{\circ} \mathrm{C}$. The brief incubations at $50^{\circ} \mathrm{C}$ caused a change in the enzyme molecules resulting in a different catalytic rate. Any given molecule was just as likely to show an increase in rate as a decrease, resulting in no significant difference in the average rate of the population. The average change in individual molecule rate was dependent upon the temperature of the brief incubation period, with a lesser average change occurring at $28^{\circ} \mathrm{C}$ and negligible change at $10^{\circ} \mathrm{C}$. A third set of experiments was similar to that of the second with the exception that it was electrophoretic mobility that was considered. This provided a similar result. Incubation at higher temperature resulted in a change in electrophoretic mobility. The probability of an individual molecules switching to a higher mobility was approximately equal to that of switching to a lower mobility, resulting in no net average change in the population. The magnitude of the changes in electrophoretic mobilities suggest that the associated conformational changes are subtle.
\end{abstract}


Studying single enzyme molecules within a population has the ability to illustrate heterogeneities within that population. Heterogeneities have been found with respect to catalytic rate, activation energy of catalysis and electrophoretic mobility for a variety of different enzymes (Xue and Yeung 1995; Craig et al. 1996; Nichols and Craig 2008). Differences between the properties of individual molecules of a given enzyme has been termed 'static heterogeneity' while variations in the properties of a given molecule over time has been termed 'dynamic heterogeneity' (Edman et al. 1999).

Static heterogeneity can be envisioned as being caused by a variety of factors including errors in transcription/translation of the primary sequence or differential post translational modifications. Differences in the properties might then result from variations in conformations as the individual molecules fold in such a way as to reach their individual energy minimums. Heat shock proteins play important roles in the proper folding of proteins (Neidhardt 1996) and therefore may potentially be a factor in static heterogeneity.

Dynamic heterogeneity most likely emerges from an ability to switch between different conformations over time at ambient or elevated temperatures due to a relatively low activation energy barrier between the conformational energy minimums. It has been shown that the full range of observed catalytic rates for a population of the enzyme $\beta$-galactosidase is far larger than the range attainable by an individual molecule over time, suggesting that interconversion between all possible active conformations is not possible once a given fold has been established (Craig and Nichols 2008). In one study, the catalytic rates of individual molecules of $\beta$ galactosidase were measured before and after several brief periods of heating. It was found that the activity of the molecules changed upon heating. However the activity for a given molecule changed randomly, both to higher or lower activity with equal probability, resulting in no net 
overall change for the population (Rojek and Walt 2014). This finding lead the authors to conclude that dynamic heterogeneity was due to interconversion between different stable and active conformations.

The differences between different active conformational states might range from relatively subtle variations in local regions of a protein to more substantial changes in overall structure. Electrophoretic mobility is dependent upon molecular shape. $\beta$-Galactosidase has been found to be electrophoretically heterogeneous. With a Stokes radius of $6.9 \mathrm{~nm}$, an average buffer radius of $0.25 \mathrm{~nm}$, an axial ratio of 1.31 and a net charge of -62.9 at $\mathrm{pH} 7.3$, a difference in conformation resulting in a change in radius of $0.3 \mathrm{~nm}$ is sufficient to account for nearly the entire range of the static electrophoretic mobility heterogeneity observed (Jacobson et al. 1994; Johansson et al. 2001; Nichols et al. 2009).

In this study we performed single enzyme molecule assays on $E$. coli $\beta$-galactosidase (EC 3.1.2.23). In E. coli, $\beta$-galactosidase is encoded by the $l a c Z$ gene which contains 3075 base pairs. The enzyme functions as a homotetramer with subunits of 1023 amino acid residues. (Jacobson et al. 1994). In the first set of experiments, in order to test if heat shock protein expression plays a role in static heterogeneity, E. coli strains carrying genomic deletions for 3 different heat shock proteins, and a strain containing no such deletions, were grown at $37^{\circ} \mathrm{C}$ and $42^{\circ} \mathrm{C}$, lysed and assays performed to determine the activity and electrophoretic static heterogeneity of the $\beta$ galactosidase produced. In a second set of experiments the change in catalytic rates of individual $\beta$-galactosidase molecules were determined before and after sequential periods of heating. In a third and final set of experiments, the change in electrophoretic mobility of individual $\beta$ galactosidase molecules were considered upon a brief period of heating. 


\section{Materials and Methods}

E. coli strains BW25113, JW0013-4, JW0054-1 and JW4103-1 were obtained from the Coli Genetic Stock Center, Yale University. Purified E. coli $\beta$-galactosidase was obtained from Sigma-Aldrich (St. Louis, MO, USA). 9H-(1,3-dichloro-9,9-dimethylacridin-2-one-7-yl)- $\beta$-Dgalactopyranoside (DDAO-gal) was obtained from Invitrogen/Molecular Probes (Eugene, OR, USA). All other reagents were from Sigma-Aldrich (St. Louis, MO, USA).

E. coli transformation: E. coli strains BW25113, JW0013-4, JW0054-1 and JW4103-1 were transformed with the plasmid pTNA containing wild-type E. coli lacZ (wtLacZ), prepared in a previous study (Craig et al. 2012). The wtLacZ was amplified from genomic DNA by using the primers 5'LacZ_SphI (5'- TTT GCA TGC ATG ACC ATG ATT ACG GAT -3') and 3'LacZ_HindIII (5'- TTT AAG CTT TTA TTT TTG ACA CCA GAC -3') (SphI and HindIII sites are underlined). PCR products were digested and ligated into the pTNA plasmid (Henn-Sax et al. 2002) which contains an ampicillin resistance cassette. The plasmid ensures a weak constitutive expression of open reading frames located in the multiple cloning site.

Cell culture and harvesting: Transformed E. coli cultures were grown overnight in LuriaBertani medium containing $100 \mu \mathrm{gml}^{-1}$ ampicillin. The suspensions were centrifuged at $3300 \mathrm{x} \mathrm{g}$ for $20 \mathrm{~min}$ at $4^{\circ} \mathrm{C}$. The pellets were re-suspended in $1 \mathrm{~mL}$ of $100 \mathrm{mM}$ HEPES (pH 7.3) containing $2 \mathrm{mM} \mathrm{MgCl} 2$ and 2\% (w/v) Sigma protease inhibitor cocktail (no metal chelators). To lyse the cells, samples were frozen in liquid nitrogen, ground, and thawed. The freeze-grindthaw cycle was repeated for a total of 5 cycles. A further $3 \mathrm{~mL}$ of $100 \mathrm{mM}$ HEPES (pH 7.3) containing $2 \mathrm{mM} \mathrm{MgCl}_{2}$ and 2\% (w/v) protease inhibitor cocktail (no metal chelators) was added to each sample and they were centrifuged at $12,000 \mathrm{xg}$. The supernatant was passed through a $0.45 \mu \mathrm{m}$ filter, diluted with an equal volume of glycerol, and stored at $-20{ }^{\circ} \mathrm{C}$ until used. 
Sample preparation: The substrate DDAO-gal contains some of the product DDAO as an impurity, which results in an increased background signal. This signal was reduced by washing of the substrate immediately prior to use. $1.7 \mu \mathrm{L}$ of $23 \mathrm{mM}$ DDAO-gal in DMSO was diluted with $198.3 \mu \mathrm{L}$ of running buffer. This solution was washed 3 times with an equal volume of toluene. To $125 \mu \mathrm{L}$ of the washed substrate was added $370 \mu \mathrm{L}$ of running buffer and $5 \mu \mathrm{L}$ of diluted enzyme.

Capillary electrophoresis (CE) instrument: Assays were performed using an inlaboratory constructed CE instrument which utilizes post-column laser-induced fluorescence (LIF) detection within a sheath flow cuvette. This instrument has been described previously (Zhao et al. 1992). The injection end of an uncoated fused silica capillary (Polymicro Technologies) and a $0.5 \mathrm{~mm}$ diameter platinum wire connected to a high voltage power supply (Spellman model CZE 2000) were placed into a buffer-containing vessel in the injection carousel and held at a positive potential. The detection end of the capillary, from which approximately 1 $\mathrm{mm}$ of the external polyimide coating was removed by flame, was inserted into a quartz sheath flow cuvette containing a 250 X $250 \mu \mathrm{m}$ inner bore (Hellma). The capillary was grounded through the sheath flow buffer within the cuvette. The $10 \mathrm{~mW}$ output at $633 \mathrm{~nm}$ of a HeNe laser (Melles Griot) was focused using a 6.3 X, N.A. 0.2 microscope objective (Melles Griot) approximately $10 \mu \mathrm{m}$ below the detection end of the capillary. Emission was collected at $90^{\circ}$ using a 60X, N.A. 0.7 microscope objective (Universe Kogaku), passed through a 670DF40 optical filter (Omega Optical) and a slit and onto a photomultiplier tube (Hamamatsu model 1477). The analog signal was collected and digitized using a Pentium 4 computer through a PCIMIO-16XE I/O board utilizing LabView ${ }^{\mathrm{TM}}$ software (National Instruments). The same board was used to control the electrophoresis voltage and the PMT bias, which was $1000 \mathrm{~V}$. 
Standard assay: Bulk solution activity of $\beta$-galactosidase was determined by monitoring the change in absorbance over time at $410 \mathrm{~nm}$ of $50 \mathrm{mM}$ HEPES (pH 7.3) containing $1 \mathrm{mM}$ $\mathrm{MgCl}_{2}, 1 \mathrm{mM}$ citrate, $0.5 \mathrm{mM}$ o-nitrophenyl- $\beta$-D-galactopyranoside and $\beta$-galactosidase incubated at $21^{\circ} \mathrm{C}$.

Continuous flow assay: The first set of experiments involved the simultaneous measurement of the catalytic rate and electrophoretic mobility of the individual $\beta$-galactosidase molecules in the lysates of the transformed E. coli strains. A $40 \mathrm{~cm}$ long, $4.4 \mu \mathrm{m}$ internal diameter, $145 \mu \mathrm{m}$ external diameter uncoated fused silica capillary was used. Data was collected at $10 \mathrm{~Hz}$. The sheath, running and sample buffers were $50 \mathrm{mM}$ HEPES (pH 7.3) containing 1 $\mathrm{mM} \mathrm{MgCl} 2$. The capillary was maintained at room temperature $\left(21^{\circ} \mathrm{C}\right)$ and sample was continuously injected at an electric field of $400 \mathrm{Vcm}^{-1}$.

A second set of experiments was performed to determine the effect of consecutive periods of heating or cooling on the catalytic rate of individual $\beta$-galactosidase molecules. Here purified $E$. coli $\beta$-galactosidase obtained from Sigma was utilized. A $60 \mathrm{~cm}$ long, $4.4 \mu \mathrm{m}$ internal diameter, $145 \mu \mathrm{m}$ external diameter uncoated fused silica capillary was used. 15 centimeters of the capillary length was suspended in the air followed by a $5 \mathrm{~cm}$ section which was attached to an aluminum pipe with electrical tape. This was followed by a $20 \mathrm{~cm}$ length of the capillary suspended in the air, a second $5 \mathrm{~cm}$ length attached to the pipe and a final $15 \mathrm{~cm}$ of length suspended in the air. Water from a recirculating heater/cooler was passed through the pipe. This separated the capillary into 5 temperature zones. The two $5 \mathrm{~cm}$ lengths were held at the set temperature of the recirculating heater-cooler and the 3 other sections at the ambient room temperature, which was $21^{\circ} \mathrm{C}$. Data was collected at $10 \mathrm{~Hz}$. Sheath, running and sample buffers 
were $50 \mathrm{mM}$ HEPES (pH 7.3) containing $1 \mathrm{mM} \mathrm{MgCl}_{2}$ and $1 \mathrm{mM}$ citrate. Sample was continuously injected into the capillary at $200 \mathrm{Vcm}^{-1}$.

A third set of experiments was performed to determine the effect of a heating or cooling period on the electrophoretic mobilities of individual molecules of $\beta$-galactosidase. Once again, the purified enzyme obtained from Sigma was used. In this set of experiments, the capillary length was separated into 3 temperature zones. $27.5 \mathrm{~cm}$ lengths at either end were suspended in the air and were separated by a $5 \mathrm{~cm}$ section which was attached to the aluminum pipe. Data was collected at $50 \mathrm{~Hz}$. Sheath, running and sample buffers were $50 \mathrm{mM}$ HEPES (pH 7.3) containing $1 \mathrm{mM} \mathrm{MgCl}_{2}$ and $1 \mathrm{mM}$ citrate. The samples were continuously injected into the capillary at an electric field of $200 \mathrm{Vcm}^{-1}$.

\section{Results and Discussion:}

Effect of differences in heat shock protein expression: In the CE continuous flow single enzyme molecule assay (Craig and Nichols 2008), fluorogenic substrate containing very dilute enzyme is continuously mobilized through a capillary. Enzyme concentration is such that approximately 5 enzyme molecules will be present, on average, per capillary volume. As an enzyme molecule traverses the capillary, and since it has a different net mobility than the product formed, it is continuously separated from the product it produces. This produces a smear of product, which upon passing a highly sensitive LIF detector yields a box shaped peak in the resultant electropherogram. If the enzyme has a less negative electrophoretic mobility than the product it forms, and therefore a higher net mobility, as was the case in the first set of experiments where a low ionic strength buffer without citrate was used, the trailing end of each peak will be due to product formed as the individual enzyme molecule entered the capillary, the 
leading end the product formed as it exited, and every point in between the activity at the corresponding time between entering and exiting. Differences between the areas of individual peaks reflect differences in the catalytic rates of the individual molecules. Differences in peak widths reflect differences in electrophoretic mobility.

The assay was performed at an enzyme concentration of 5 molecules of enzyme per capillary volume $(6.1 \mathrm{~nL})$, which corresponds to a concentration of $1.4 \mathrm{fM}$. In the past, very dilute concentrations of multimeric enzymes, including $\beta$-galactosidase, were prepared in the presence of proteins such as BSA in an attempt to prevent subunit dissociation and loss of activity (Rotman 1961). Such 'stabilizing' proteins were not used in this study. Experimental evidence has shown that this concern over denaturation at high dilution is without merit (Craig and Nichols 2012). $\beta$-Galactosidase activity has been shown to remain linear with concentration down to the lowest concentration assayed which was $4.8 \mathrm{fM}$ (Eggertson and Craig 1999) in the absence of additional protein. For alkaline phosphatase in the absence of additional protein activity also remained linear with concentration down to the lowest value detected, which was $460 \mathrm{aM}$ (Craig et al 1996). That activity remained linear with concentration indicates that subunit dissociation does not occur.

Figure 1 shows the resultant electropherogram for the continuous flow assay of $\beta$ galactosidase from an E. coli lysate. There is an initial shift in the background as the substrate DDAO-gal starts to elute from the capillary. A second shift occurs as DDAO, present as an impurity in the DDAO-gal and formed due to non-enzymatic hydrolysis, begins to migrate past the detector. Following this shift, 8 box-shaped peaks are observed. Each represents the product made as an individual enzyme molecule traversed the capillary. The time of the first and second 
shift were used to calculate the mobility of the electroosmotic flow and the electrophoretic mobility of the DDAO respectively using the following equations:

$$
\mu_{\mathrm{EOF}}=\mathrm{L} / \mathrm{t}_{\mathrm{m}, \mathrm{DDAO}-\mathrm{gal}} \mathrm{E}
$$

where $\mu_{\mathrm{EOF}}$ is the mobility of the electroosmotic flow, $\mathrm{L}$ is the capillary length, $\mathrm{t}_{\mathrm{m}, \mathrm{DDAO} \text {-gal }}$ is the time of the first background shift and $\mathrm{E}$ is the electric field.

$$
\mu_{\mathrm{DDAO}}=\left(\mathrm{L} / \mathrm{t}_{\mathrm{mDDAO}} \mathrm{E}\right)-\mu_{\mathrm{EOF}}
$$

where $\mu_{\mathrm{DDAO}}$ is electrophoretic mobility of the DDAO and $t_{\mathrm{mDDAO}}$ is the time of the second background shift.

The width of each peak was used to calculate the electrophoretic mobility of each enzyme molecule according to the following equation:

$$
\mu_{\text {enzyme }}=\left\{\mathrm{L} /\left(\mathrm{t}_{\mathrm{mDDAO}}-\mathrm{w}\right) \mathrm{E}\right\}-\mu_{\mathrm{EOF}}
$$

where $\mu_{\text {enzyme }}$ is electrophoretic mobility of the given enzyme molecule and $w$ is the width of each box-shaped peak.

Since the enzyme molecules had different electrophoretic mobilities, their times for traveling the length of the capillary, and therefore the enzyme incubation time, differed. This transit time, $\mathrm{t}$, was calculated according to the equation:

$$
\mathrm{t}=\mathrm{L} /\left(\mu_{\mathrm{EOF}}+\mu_{\text {enzyme }}\right) \mathrm{E}
$$

The area of each box-shaped peak was compared to that of standard injections of DDAO, performed daily in triplicate, and divided by the transit time in order to determine the catalytic rate of each enzyme molecule (Craig and Nichols 2008; Craig et al. 2013).

Crude lysates of the E. coli strains BW25113, JW0013, JW0054 and JW4103 were assayed. BW25113, and all strains derived from it, contains a genomic deletion for LacZ and therefore does not produce $\beta$-galactosidase. BW25113 is the parent $E$. coli strain from which the 
Keio collection was derived. The Keio collection, which strains JW0013, JW0054 and JW4103 are members of, is a set of single gene deletion mutants of E. coli K-12 (Yamamoto et al. 2009). JW0013 has a deletion for the heat shock protein DnaK. JW0054 has a deletion for DnaJ. JW4103 contains a deletion for the heat shock protein GroEL. In bacteria, DnaK-DnaJ-GrpE and GroEL-GroES are the main chaperon systems for the prevention of misfolding and aggregation of newly formed polypeptides. Protein misfolding increases upon stress, such as an increase in growth temperature from 37 to $42^{\circ} \mathrm{C}$, and as such the expression of these systems is increased. In E. coli $\beta$-galactosidase utilizes the DnaK-DnaJ-GrpE but not the GroEL-GroES system. It is for this reason that these strains were used in this study (Neidhardt 1996; Thomas \& Baneyx 1996). All 4 E. coli strains were transformed with pTNA containing wtLacZ. Cultures of each were grown at 37 and $42^{\circ} \mathrm{C}$ (heat shock), lysed and assayed to determine the effect of heat shock and heat shock protein deletions on the distributions of catalytic rates and electrophoretic mobility. This experiment was designed to test the effect of heat shock on the distribution of catalytic rates and electrophoretic mobilities of $\beta$-galactosidase produced in E. coli strains containing their full wild-type complement of heat shock proteins and strains containing a deletion for the 3 different heat shock proteins. The hypothesis was that since DnaK-DnaJ-GrpE is involved in the folding of $\beta$-galactosidase and GroEL-GroES is not, and differences in catalytic rates have been attributed to differences in conformation (Rojek and Walt 2014), altering heat shock protein expression of one system might manifest an effect on the static heterogeneity of catalytic rates or electrophoretic mobilities, whereas altering the other should not.

The determined average catalytic rate and electrophoretic mobility of the enzyme from each lysate are shown in Table 1. 
In a previous study, single molecule assays performed on lysates of E. coli strain BW25113 transformed with plasmid containing wtLacZ produced peaks in the resultant electropherogram. Assays of lysates of BW25113, which contains a deletion for LacZ, produced no detectable peaks under identical conditions (Craig et al. 2012). Measurements of electrophoretic mobility have been made on highly purified preparations of $\beta$-galactosidase as well as crude homogenates. The averages and range of mobilities were indistinguishable (Nichols and Craig 2008). This suggests that despite the presence of other proteins in the lysates, all peaks produced in this assay can be attributed to $\beta$-galactosidase. Furthermore, electrophoretic mobility measurements are also not affected by the presence of additional cellular material.

Assays of $\beta$-galactosidase from different wild-type strains of $E$. coli have been shown to have average catalytic rates that differ by up to a few fold (Craig et al. 2003). As such, caution should be used when comparing the data obtained from the different strains used, despite being all derived from the same parent strain. All samples gave relatively similar average catalytic rates. There was no clear relationship between growth temperature and average rate. However for all samples the average electrophoretic mobility was slightly more negative $(\mathrm{P}<0.05)$ for every strain in the sample that was grown under heat shock conditions. Figure 2 shows the catalytic rate and electrophoretic mobility for each of the 1211 molecules assayed. Catalytic rate was found to be independent of electrophoretic mobility $\left(r^{2}=0.03\right)$.

Since the trailing edge of each box-shaped peak was formed as the enzyme molecule entered the capillary it represents the product that was formed first. This edge of the peak is less sharp than that of the leading edge since there was more time for diffusion to occur. However, in the case of 9 of a total of 1211 peaks analyzed the opposite was noted. This indicates that the net 
mobility of these enzyme molecules were less than that of the DDAO product. The population of enzyme molecules showed a distribution of mobilities and these 9 molecules populated the edge of this distribution. For these 9 molecules, the mobility was determined using the equation:

$$
\mu_{\text {enzyme }}=\left\{\mathrm{L} /\left(\mathrm{t}_{\mathrm{mDDAO}}+\mathrm{w}\right) \mathrm{E}\right\}-\mu_{\mathrm{EOF}}
$$

This set of experiments showed no clear effect of alterations in heat shock protein expression on the heterogeneity of $\beta$-galactosidase.

GroeL-GroES have been found to not be involved in the proper folding and acquisition of activity of $\beta$-galactosidase fusion proteins. $\beta$-Galactosidase subunits are too large to be encapsulated inside GroeL-GroES, althought interactions between $\beta$-galactosidase and this chaperon complex have been reported (Thomas and Baneyx 1996; Garcia-Fruitos et al. 2005). Because of this, no differences between the heterogeneity of the enzyme from the JW4103 strain, which does not express GroEL, and the wild-type strain was not unexpected.

Folding of $\beta$-galactosidase and $\beta$-galactosidase fusion proteins utilizes the DnaK-DnaJGrpE system. $\alpha$-Complementation of $\beta$-galactosidase is also dependent upon this system. However, this system increases the folding yield of the active enzyme. A significant proportion of the enzyme attains activity in its absence. Of the fraction that folds, a subpopulation have been found to be 'defective' in that they retain only about $10 \%$ of the specific activity of the fully functional $\beta$-galactosidase (Thomas and Baneyx 1996; Ferreira and Alix 2002; Young et al. 2004; Garcia-Fruitos et al. 2005; McCallister et al. 2015).

Our assay assesses only the individual $\beta$-galactosidase molecules which have sufficient activity for single molecule detection. That we found no difference between the heterogeneity of the enzyme obtained from the wild-type strain and strains JW0013 and JW0054, which have deletions for DnaK and DnaJ respectively, may reflect that only the fraction of $\beta$-galactosidase 
which is properly folded was detected. Another possibility may be that the presence of other heat shock proteins may have been able to compensate for the absence of either DnaK or DnaJ.

Effect of brief incubations at increased or decreased temperature on catalytic rate: In the continuous flow assay, if a region of the capillary is maintained at a different temperature than the remainder of the capillary, as the enzyme molecule traverses this region its catalytic rate will differ. This results in the height of the corresponding portion of the box-shaped peak to increase or decrease, depending on whether the temperature was higher or lower than in the remainder of the capillary.

Under low ionic strength conditions, citrate binds to $\beta$-galactosidase rendering its electrophoretic mobility more negative, thereby decreasing its net mobility to a point where it is less than DDAO (Craig et al. 2013). In the second and third set of experiments the buffer contained $1 \mathrm{mM}$ citrate. Since under these conditions the enzyme has a lower net mobility than does the DDAO, the product formed as the enzyme travels the length of the capillary advances ahead of it. Therefore it is the product that was formed as the enzyme entered the capillary that reaches the detector first. Under these conditions, the box-shaped peaks are mirror image. The leading edge represents the product formed as the enzyme entered the capillary, the trailing edge the product as it exited, and every point in between the corresponding time between entering and exiting.

In this second set of experiments, $\beta$-galactosidase molecules were assayed whereupon the capillary was divided into 5 zones. The longer $1^{\text {st }}, 3^{\text {rd }}$ and $5^{\text {th }}$ zones were held at the ambient room temperature of $21^{\circ} \mathrm{C}$. The temperatures of the shorter $2^{\text {nd }}$ and $4^{\text {th }}$ zones were controlled by the recirculating heater/cooler which was set at 50,28 or $10^{\circ} \mathrm{C}$. If the short period of heating or cooling occurring as the enzyme crossed the $2^{\text {nd }}$ and $4^{\text {th }}$ zones resulted in an alteration in the 
enzyme, this resulted in a change in the height of the plateaus corresponding to the $1^{\text {st }}, 3^{\text {rd }}$ and $5^{\text {th }}$ zones of the capillary.

Figure 3 shows an electropherogram resulting from a single $\beta$-galactosidase molecule traveling the length of the capillary while the $2^{\text {nd }}$ and $4^{\text {th }}$ zones were maintained at $50^{\circ} \mathrm{C}$. The height of the plateau at the leading end of the peak represents the catalytic rate of the enzyme molecule as it traversed the $1^{\text {st }}$ zone $\left(21^{\circ} \mathrm{C}\right)$ of the capillary. The variation in signal over time is similar to that of the background noise, indicating that the catalytic rate was approximately constant over time as the enzyme travelled across this region (Craig and Nichols 2008). This plateau is followed by a peak which represents the higher catalytic rate supported at $50^{\circ} \mathrm{C}$ as the enzyme crossed the $2^{\text {nd }}$ zone of the capillary. Upon reaching the third zone, which was again at $21^{\circ} \mathrm{C}$, the catalytic rate was again approximately constant over time, but was somewhat different than it was in the $1^{\text {st }}$ zone. This was followed by a second elevated signal as the enzyme traversed the $4^{\text {th }}$ zone, which was also held at $50^{\circ} \mathrm{C}$. Finally at the trailing side of the peak there is a third plateau which resulted from the enzyme molecule travelling across the $5^{\text {th }}$ zone of the capillary. In the analysis of the data, the baseline signal was removed and the height of the average signal of the plateaus due to the enzyme activity in the $1^{\text {st }}, 3^{\text {rd }}$ and $5^{\text {th }}$ zones of the capillary determined. A total of 24 peaks were analyzed. When the $2^{\text {nd }}$ and $4^{\text {th }}$ zones of capillary were maintained at $28^{\circ} \mathrm{C}$, the peaks looked almost identical with the exception of the signal heights in the $2^{\text {nd }}$ and $4^{\text {th }}$ zones were not as high (Figure 4 ). A total of 22 peaks were analyzed when $28^{\circ} \mathrm{C}$ was used. Figure 5 shows the resultant electropherogram from the travel of a single enzyme molecule down the capillary when zones 2 and 4 were maintained at $10^{\circ} \mathrm{C}$. The electropherogram is similar to that depicted in Figure 3 with the exception that the signal height 
in zones 2 and 4 are lower than that in the $1^{\text {st }}, 3^{\text {rd }}$ and $5^{\text {th }}$ zones. This is due to the lower activity of the enzyme at $10^{\circ} \mathrm{C}$ as compared to $21^{\circ} \mathrm{C}$.

The catalytic rates of 24,22 and 22 molecules were determined at $21^{\circ} \mathrm{C}$ (zones 1,3 and 5) after periods of incubation (zones 2 and 4) at 50,28 and $10^{\circ} \mathrm{C}$ respectively. The data is shown in Table 2. The data was analyzed using analysis of variance (ANOVA) with any differences among the catalytic rates at the 5\% level considered significant. Average catalytic rates for all the molecules studied at a given temperature determined from zones 1, 3 and 5 were not found to differ significantly from one another when zones 2 and 4 were held at any of the temperatures tested. Average rates from zones 1, 3 and 5 were compared between the runs where zones 2 and 4 were held at the different temperatures and again no significant differences were found. Similarly, no significant differences in variance were observed. The averages and variances were all indistinguishable. This indicates that in all cases the catalytic heterogeneities were also indistinguishable.

The relative difference in rate for each individual enzyme molecule between zones 1 and 3, and between zones 3 and 5 were also determined. When zones 2 and 4 were held at $50^{\circ} \mathrm{C}$, the rates observed in zone 1 and zone 3 differed on average by $22 \%$ for each enzyme molecules. The rates observed in zones 3 and 5 differed on average by $43 \%$. However, for one molecule the rate increased 6-fold. If this outlying point is discarded, the average difference was $19 \%$. The number of molecules whose activity increased after each heating period was approximately equal to those which decreased, resulting in no net change in average rate or variance. When zones 2 and 4 were held at $28^{\circ} \mathrm{C}$, the individual molecules rate changed by an average of 7 and $6 \%$ between zones 1 and 3 and between 3 and 5 respectively. Again, approximately the same number of molecules increased in rate as decreased, rendering the average rate unchanged. When zones 2 
and 4 were held at $10^{\circ} \mathrm{C}$, the average changes in rate for the individual molecules were found to be 4 and 4\%. As previously, a roughly equal number of molecules increased in average rate as decreased.

This data suggests that initially there is a heterogeneous population. A period of heating at $50^{\circ} \mathrm{C}$ altered the catalytic rate of the individual molecules by about $20 \%$ on average. However about the same fraction of molecules increased in rate as decreased, rendering the distribution of activities unchanged. A second period of heating had the same effect. Heating periods at $28^{\circ} \mathrm{C}$ had a similar effect but the average change in rate was more modest. Periods of incubation at $10^{\circ} \mathrm{C}$ showed negligible changes in average rate.

Bulk solution assays on large ensembles of the enzyme were performed after a 2 min period of incubation at 10,28 or $50^{\circ} \mathrm{C}$. The activity of the bulk enzyme solution after incubation at 10 and $28^{\circ} \mathrm{C}$ did not differ from that which was untreated. However, incubation at $50^{\circ} \mathrm{C}$ lead to a decrease in activity of approximately $8 \%$. In our single molecule assay, we saw no net change in average activity. However, in this assay we assessed the activity of only those individual enzyme molecules that remained active after the incubations at $50^{\circ} \mathrm{C}$. Any enzyme molecules which denatured were not taken into account. In the bulk solution assay, denaturation of a portion of the enzyme results in a decrease in bulk activity, which is what was measured. Previous work has shown that a fraction of the individual $\beta$-galactosidase molecules denatures upon a short incubation at $50^{\circ} \mathrm{C}$ (Craig and Nichols 2008).

Determination of the relative change in activity of a given molecule does not lend itself to suggest what type of conformational changes might be occurring. A very small conformational change occurring near the active site could be envisaged as having a dramatic change in catalytic rate whereas very little effect if it were to occur elsewhere in the protein structure. Furthermore, 
a large change in conformation occurring far from the active site could result in very little change in catalytic rate.

A similar study has been reported by Rojek and Walt (2014). Their system allowed for the measurement of the change in catalytic rate of a much larger number of individual molecules of $\beta$-galactosidase upon brief periods of sequential heating to $47^{\circ} \mathrm{C}$, but they did not test the effect of different temperatures. Our results at $50^{\circ} \mathrm{C}$ are in complete agreement with their findings at $47^{\circ} \mathrm{C}$. The population of enzyme molecules was initially heterogeneous with respect to heating. After each heating period, the average and range of activities of the population did not change. However, when individual molecules were assessed, the catalytic rates appeared to change randomly upwards or downwards. However, the experimental approach used by Rojek and Walt did not involve electrophoresis and therefore no measurements of electrophoretic mobility were made.

\section{Effect of brief incubations at increased or decreased temperature on electrophoretic} mobility: In third set of experiments, only the central $5 \mathrm{~cm}$ of the capillary was attached to the heating block, separating the capillary into 3 zones. The first $27.5 \mathrm{~cm}$ long zone (zone 1) remained at room temperature, the central $5 \mathrm{~cm}$ zone (zone 2) was maintained at 50,28 or $10^{\circ} \mathrm{C}$ with the use of a recirculating heater/cooler, and the final $27.5 \mathrm{~cm}$ zone (zone 3 ) remained at room temperature. In this experiment it was enzyme mobility that was the point of interest. The use of two longer zones at room temperature and collecting data at $50 \mathrm{~Hz}$ made the measurement of peak widths more accurate. Figure 6 shows the resultant electropherogram when the central zone of the capillary was held at $50^{\circ} \mathrm{C}$. The shape of the peak is similar to that in Figure 3 with the exception that there is only a single region where the peak height is elevated. 2 widths were measured; the width from the half maximal height of the leading edge of the peak to the mid- 
point of the central raised portion of the peak, and the width from the mid-point of the central raised portion of the peak to the half-maximal height of the trailing edge of the peak. These widths were taken to represent the relative mobilities of the enzyme prior to the short heating period at $50^{\circ} \mathrm{C}$ and that after this heating period. Measurements were made on the individual molecules when the temperature-controlled region of the capillary was maintained at $50(\mathrm{~N}=21)$, $28(\mathrm{~N}=18)$ and $10^{\circ} \mathrm{C}(\mathrm{N}=20)$. Room temperature was $21^{\circ} \mathrm{C}$. For each enzyme molecule 2 width measurements were made. The data is shown in Table 3.

The data was analyzed using ANOVA with any differences at the 5\% level considered significant. The average and variances in the width corresponding to the $1^{\text {st }}$ and $3^{\text {rd }}$ zones did not differ significantly from one another either within one temperature group or between the temperature groups. The differences in widths corresponding to zone 1 and 3 were compared for each individual molecule at each of the temperatures used for zone 2 . When zone 2 was maintained at $50^{\circ} \mathrm{C}$, the width of zone 3 differed on average by $8 \%$ from that of zone 1 . Roughly an equal proportion of molecules showed an increase in width as showed a decrease in width. The same was found when 28 and $10^{\circ} \mathrm{C}$ were used, with the average changes in widths being $5 \%$ and $3 \%$ respectively.

This data suggests that as the individual molecules were briefly heated to $50^{\circ} \mathrm{C}$ there was an average change in widths of $8 \%$, with an equal portion of molecules showing an increase in mobility as those showing a decrease, resulting in no change in the average or variance. A $28^{\circ} \mathrm{C}$ incubation showed the same effect although the average change was reduced. The same pattern was maintained at $10^{\circ} \mathrm{C}$, although the average change was minimal.

This set of experiments was not concerned with the activity of the enzyme molecules prior to and after the heating or cooling periods. However, with respect to this activity, the same 
general pattern as that observed in the second set of experiments was noted. Plateau heights for each individual molecule were just as likely to increase as decrease and the amount of change was temperature dependent.

Electrophoretic theory allows one to predict how much of a change in an enzyme's shape or charge is required to illicit a given change in electrophoretic mobility (Compton and O'Grady 1991; Adamson and Reynolds 1997). An average 8\% change in the widths of the box-shaped peaks corresponds to a calculated change in electrophoretic mobility of $1 \times 10^{-6} \mathrm{~cm}^{2} \mathrm{~V}^{-1} \mathrm{~s}^{-1} \cdot \beta-$ Glactosidase has a Stokes radius of $6.9 \mathrm{~nm}$, an average buffer radius of $0.25 \mathrm{~nm}$, an axial ratio of 1.31 and a net charge of -62.9 at $\mathrm{pH} 7.3$ (Nichols et al. 2009). If a conformational change resulted in a change in Stokes radius of less than $0.1 \mathrm{~nm}$, this is sufficient to result in a change in mobility of $1 \times 10^{-6} \mathrm{~cm}^{2} \mathrm{~V}^{-1} \mathrm{~s}^{-1}$. Each monomer of $\beta$-galactosidase contains 5 independently folding domains. The first 50 amino acid residues of each monomer are in an extended form with the first 12 residues being highly disordered. Each monomer contains several solvent exposed loops including those from residues 578-583, 654-690 and 727-733, all of which are highly mobile with multiple possible conformations (Juers et al. 2000; Matthews 2005). Site-directed mutagenesis studies of staphlococcyl nuclease have shown that the loss of a single hydrogen bond altered the CE determined electrophoretic mobility of the enzyme by $3 \times 10^{-6} \mathrm{~cm}^{2} \mathrm{~V}^{-1} \mathrm{~s}^{-1}$. The conversion of a single peptide bond from cis to trans, due to the substitution of a glycine for an alanine resulted in a change in mobility of $2 \times 10^{-6} \mathrm{~cm}^{2} \mathrm{~V}^{-1} \mathrm{~s}^{-1}$ (Kalman et al. 1995). The conformational changes associated with the incubations at elevated temperature are likely quite subtle and do not involves large shifts in structural elements. This change in mobility due to dynamic heterogeneity is far smaller than the range of mobilities due to the static heterogeneity. 
This implies that once a given enzyme molecule adopts its conformation, the full range of possible other conformations cannot be accessed through dynamic heterogeneity.

Summary: Rojek and Walt (2014) found that individual molecules of $\beta$-galactosidase can be induced to change conformation by short periods of incubation at elevated temperature. They noted that after a heating period an enzyme molecule was equally likely to show an increase in activity as a decrease, resulting in no net change in the average catalytic rate of the population. They proposed that this is due to switching from one stable active conformation to another stable conformation with a different catalytic rate upon heating. Our findings, which used the same enzyme but a very different experimental approach, are entirely consistent with this proposal: Individual molecules of $\beta$-galactosidase can be converted into different conformations with different stable activities though periods of increased temperatures. However, there is no net change in the population due to each molecule being just as likely to show an increase in activity as a decrease. This change in conformation cannot be explained by the binding of allosteric effectors, since the buffer composition remained constant. In addition, we found that the average amount of change in activity which occurred was dependent upon the temperature of the brief incubation temperature. Furthermore, our system was capable of measuring electrophoretic mobility which gave the same result as our measurements of catalytic rate. Individual enzyme molecules, after a brief heating period, demonstrated a change in electrophoretic mobility. The probability of a molecule increasing or decreasing its mobility were found to be equal, resulting in no net change in the average mobility of the population. Again, the average change was found to be temperature dependent. This study further supports the proposal that dynamic heterogeneity is due to conformational changes in individual molecules which results in differences in catalytic rate and in electrophoretic mobility and suggests that the conformational changes are subtle. This 
study also showed no clear effect of heat shock protein expression on the static heterogeneity of $\beta$-galactosidase.

\section{Acknowledgements}

This study was supported by a grant from the Natural Sciences and Engineering Research Council. We thank Shakhawat Hossain for his help with the statistical analysis.

\section{References}

Adamson, N.J., and Reynolds, E.C. 1997. Rules relating electrophoretic mobility, charge and molecular size of peptides and proteins. J. Chromatogr. B. 699: 133-147.

Compton, B.J., and O’Grady, E.O., 1991. Role of charge suppression and ionic strength in free zone electrophoresis of proteins. Anal. Chem. 63: 2597-2602.

Craig, D.B., Arriaga, E.A., Wong, J. C.Y., and Dovichi, N.J. 1996. Studies on single alkaline phosphatase molecules: reaction rate and activation energy of a reaction catalyzed by a single molecule and the effect of thermal denaturation - the death of an enzyme. J. Am. Chem. Soc. 118: $5245-5253$.

Craig, D.B., Wong, J.C.Y., and Dovichi, N.J. 1996. Detection of attomolar concentrations of alkaline phosphatase by capillary electrophoresis using laser-induced fluorescence detection. Anal. Chem. 68: 697-700. 
Craig, D.B., Bayaraa, B, Lee, D., and Charleton, J. 2013. Effect of induction temperature and partial thermal denaturation on the catalytic and electrophoretic heterogeneity of $\beta$-galactosidase from two Escherichia coli strains. J. Liq. Chromatogr. R. T. 36: 2944-2959.

Craig, D.B., Nachtigall, J.T., Ash, H.L., Shoemaker, G.K., Dyck, A.C., Wawrykow, T.M.J. and Gudbjartson, H.L. 2003. Differences in the average single molecule activities of E. coli $\beta$ galactosidase: Effect of source, enzyme molecule age and temperature of induction. J. Prot. Chem. 22: 555-561.

Craig, D.B., Schwab, T., and Sterner, R. 2012. Random mutagenesis suggests that sequence errors are not a major cause of variation in the activity of individual molecules of $\beta$ galactosidase. Biochem. Cell Biol. 90: 540-547.

Craig, D.B., and Nichols, E.R. 2012. "Sample preparation for single molecule enzymology using capillary electrophoresis with fluorescence detection" in "Comprehensive sampling and sample preparation", volume 3; J Pawliszyn, XC Le, XF Li, HK Lee Eds; Elsevier, Academic Press: Oxford UK, pp 323-337.

Craig, D.B., and Nichols, E.R. 2008. Continuous flow assay for the simultaneous measurement of the electrophoretic mobility, catalytic activity and its variation over time of individual molecules of Escherichia coli $\beta$-galactosidase. Electrophoresis 29: 4298-4303. 
Edman, L., Foldes-Papp, Z., Wennmalm, S., and Rigler, R. 1999. The fluctuating enzyme: A single molecule approach. Chem. Phys. 247: 11-22.

Eggertson, M.J., and Craig, D.B. 1999. $\beta$-Galactosidase assay using capillary electrophoresis laser-induced fluorescence detection and resorufin- $\beta$-D-galactopyranoside as substrate. Biomed. Chromatogr. 13: 516-519.

Ferreira, N.J., and Alix, J.-H. 2002. The DnaK chaperone is necessary for $\alpha$-complementation of $\beta$-galactosidase in Eschyerichia coli. J. Bacteriolog. 184: 7047-7054.

Garcia-Fruitos, E., Carrio, M.M., Aris, A., and Villaverde, A. 2005. Folding of a misfoldingprone $\beta$-galactosidase in absence of DnaK. Biotechnology and Bioengineering 90: 869-875.

Henn-Sax, M., Thoma, R., Schmidt, S., Hennig, M., Kirschner, K., and Sterner, R. 2002. Two $(\beta \alpha) 8$-barrel enzymes of histidine and tryptophan biosynthesis have similar reaction mechanisms and common strategies for protecting their labile substrates. Biochemistry 41: 12032-12042.

Jacobson, R.H., Zhang, X.J., DuBose, R.F., and Matthew, B.W. 1994. Three dimensional structure of $\beta$-galactosidase from E. coli. Nature 369: 761-766.

Johansson, E., Majka, J., and Burgers, M.J. 2001. Structure of DNA polymerase $\delta$ from Saccharomyces cerevisiae. J. Biol. Chem. 276: 43824-43828. 
Juers, D.H., Jacobson, R.H., Wigley, D., Zhang, X.J., Huber, R.E., Tronrud, D.E., and Matthews, B.W. 2000. High resolution refinement of $\beta$-galactosidase in a new crystal form reveals multiple metal-binding sites and provides a structural basis for $\alpha$-complementation. Pro. Sci. 9: 16851699.

Kalman, F., Ma, S., Fox, R.O., and Horvath, C. 1995. Capillary electrophoresis of S. nuclease mutants. J. Chromatogr. A 705: 135-154.

Matthews, B.W. 2005. The structure of E. coli $\beta$-galactosidase. C. R. Biol. 328: 549-556.

McCallister, C., Siracusa M.C., Shirazi, F., Chalkia, D. and Nikolaidis, N. 2015. Functional diversification and specialization of cytosolic 70-kDa heat shock proteins. Scientific Reports 5, article number 9363.

Nichols, E.R., and Craig, D.B. 2008. Measurement of the differences in electrophoretic mobilities of individual molecules of $E$. coli $\beta$-galactosidase provides insight into structural differences which underlie enzyme microheterogeneity. Electrophoresis 29: 4257-4269.

Nichols, E.R., Shadabi, E. and Craig, D.B. 2009. Effect of alteration of translation error rate on enzyme microheterogeneity as assessed by variation in single molecule electrophoretic mobility and catalytic activity. Biochem. Cell Biol. 87: 517-529. 
Neidhardt, F.C., ed. Escherichia Coli and Salmonella: Cellular and Molecular Biology. 2nd ed. Washington, D.C.: ASM, 1996.

Rojek, M.J., and Walt, D.R. 2014. Observing single enzyme molecules interconvert between active states upon heating. Plos One 9: 1-7.

Rotman, B. 1961. Measurement of the activity of single molecules of $\beta$-D-galactosidase.

Biochemistry 47: 1981-1991.

Thomas, J.G., and Baneyx, F. 1996. Protein folding in the cytoplasm of Escherichia coli: requirements for the DnaK-DnaJ-GrpE and GroEL-GroeS molecular chaperon machines. Mol. Microbiol. 21: 1185-1196.

Xue, Q. and Yeung, E.S. 1995. Differences in the chemical reactivity of individual molecules of an enzyme. Nature 373: 681-683.

Yamamoto, N., Nakahigashi, K., Nakamichi, T., Yoshino, M., Takai, Y., Touda, Y., Furubayashi, A., Kinjyo, S., Dose, H., Hasegawa, M., Datsenko, K.A., Nakayashiki, T, Tomita, M, Wanner, B.L., and Mori H. 2009. Update on the Keio collectionof Escherichia coli singlegene deletion mutants. Mol. Syst. Biol. 5: 335.

Young, J.C., Agashe, V.R., Siegers, K., and Hartl, F.U. 2004. Pathways of chaperone-mediated protein folding in the cytosol. Nature Reviews Molecular Cell Biology 5: 781-791. 
Zhao, J.-Y., Chen, D.-Y., and Dovichi, N. J. 1992. Low-cost laser-induced fluorescence detector for micellar capillary zone electrophoresis. Detection at the zeptomol level of tetramethylrhodamine thiarbamyl amino acid derivatives. J. Chromatogr. 608: 117-120. 


\section{Table 1}

\begin{tabular}{|l|l|l|l|l|}
\hline Strain & $\begin{array}{l}\text { growth } \\
\text { temp }\end{array}$ & $\mathrm{N}$ & $\begin{array}{l}\text { catalytic rate } \\
\left(\mathrm{min}^{-1}\right)\end{array}$ & $\begin{array}{l}\mu_{\text {enzyme }} \\
\left(\mathrm{x} 10^{-4} \mathrm{~cm}^{2} \mathrm{~V}^{-1} \mathrm{~s}^{-1}\right)\end{array}$ \\
\hline BW25113 & $37^{\circ} \mathrm{C}$ & 145 & $27,000 \pm 8,000$ & $-1.62 \pm 0.05$ \\
\hline BW25113 & $42^{\circ} \mathrm{C}$ & 154 & $31,000 \pm 9,000$ & $-1.67 \pm 0.06$ \\
\hline JW0013 & $37^{\circ} \mathrm{C}$ & 165 & $29,000 \pm 10,000$ & $-1.60 \pm 0.06$ \\
\hline JW0013 & $42^{\circ} \mathrm{C}$ & 152 & $32,000 \pm 10,000$ & $-1.64 \pm 0.04$ \\
\hline JW0054 & $37^{\circ} \mathrm{C}$ & 144 & $36,000 \pm 17,000$ & $-1.59 \pm 0.05$ \\
\hline JW0054 & $42^{\circ} \mathrm{C}$ & 149 & $30,000 \pm 8,000$ & $-1.61 \pm 0.06$ \\
\hline JW4103 & $37^{\circ} \mathrm{C}$ & 151 & $30,000 \pm 10,000$ & $-1.63 \pm 0.06$ \\
\hline JW4103 & $42^{\circ} \mathrm{C}$ & 151 & $29,000 \pm 9,000$ & $-1.64 \pm 0.03$ \\
\hline
\end{tabular}

Table 1: The average and standard deviations of the catalytic rates and enzyme electrophoretic mobilities for $\beta$-galactosidase produced in 4 different strains of $E$. coli at 37 and $42^{\circ} \mathrm{C}$ are shown. 


\section{Table 2}

\begin{tabular}{|l|l|l|l|}
\hline zone 2 and 4 & zone 1 height & zone 3 height & zone 5 height \\
temperature & $0.0561 \pm 0.0270$ & $0.0577 \pm 0.0282$ & $0.0566 \pm 0.0278$ \\
\hline $10^{\circ} \mathrm{C}$ & $0.0487 \pm 0.0202$ & $0.0476 \pm 0.0202$ & $0.0484 \pm 0.0201$ \\
\hline $58^{\circ} \mathrm{C}$ & $0.0596 \pm 0.0286$ & $0.0502 \pm 0.0258$ & $0.0524 \pm 0.0245$ \\
\hline $50^{\circ} \mathrm{C}$ & & & \\
\hline
\end{tabular}

Table 2: The average height and standard deviation of zones 1, 3 and 5 are shown when zones 2 and 4 were held at $10(\mathrm{~N}=22), 28(\mathrm{~N}=22)$ and $50^{\circ} \mathrm{C}(\mathrm{N}=24)$. 
Table 3

\begin{tabular}{|l|l|l|}
\hline zone 2 temperature & zone 1 width (s) & zone 3 width (s) \\
\hline $10^{\circ} \mathrm{C}$ & $40.8 \pm 18.3$ & $40.5 \pm 18.5$ \\
\hline $28^{\circ} \mathrm{C}$ & $35.0 \pm 12.5$ & $34.5 \pm 12.8$ \\
\hline $50^{\circ} \mathrm{C}$ & $34.5 \pm 14.2$ & $35.2 \pm 14.7$ \\
\hline
\end{tabular}

Table 3: The average width and standard deviation of zones 1 and 3 are shown when zone 2 was held at $10(\mathrm{~N}=20), 28(\mathrm{~N}=18)$ and $50^{\circ} \mathrm{C}(\mathrm{N}=21)$. 
Figure 1

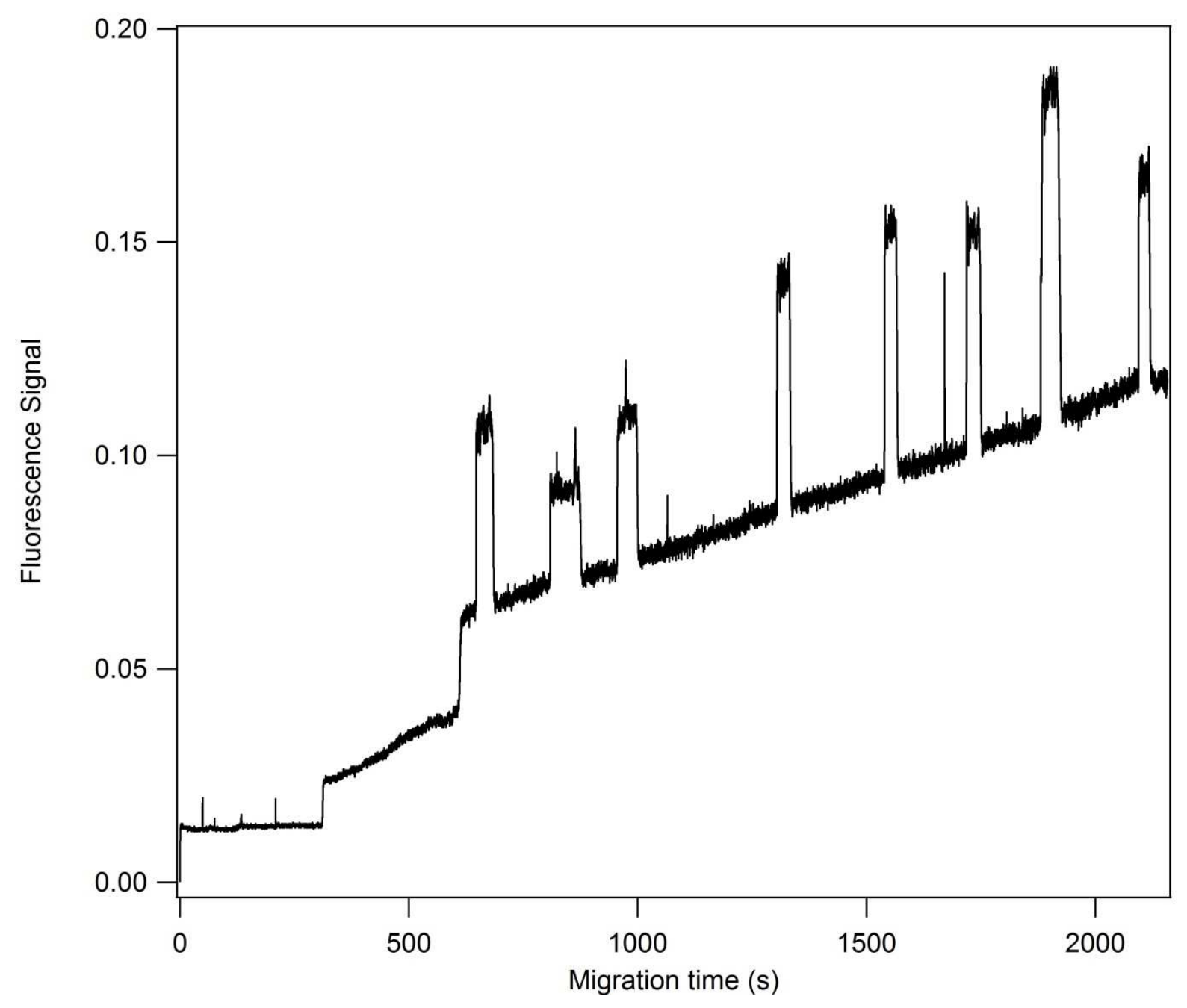


Figure 2

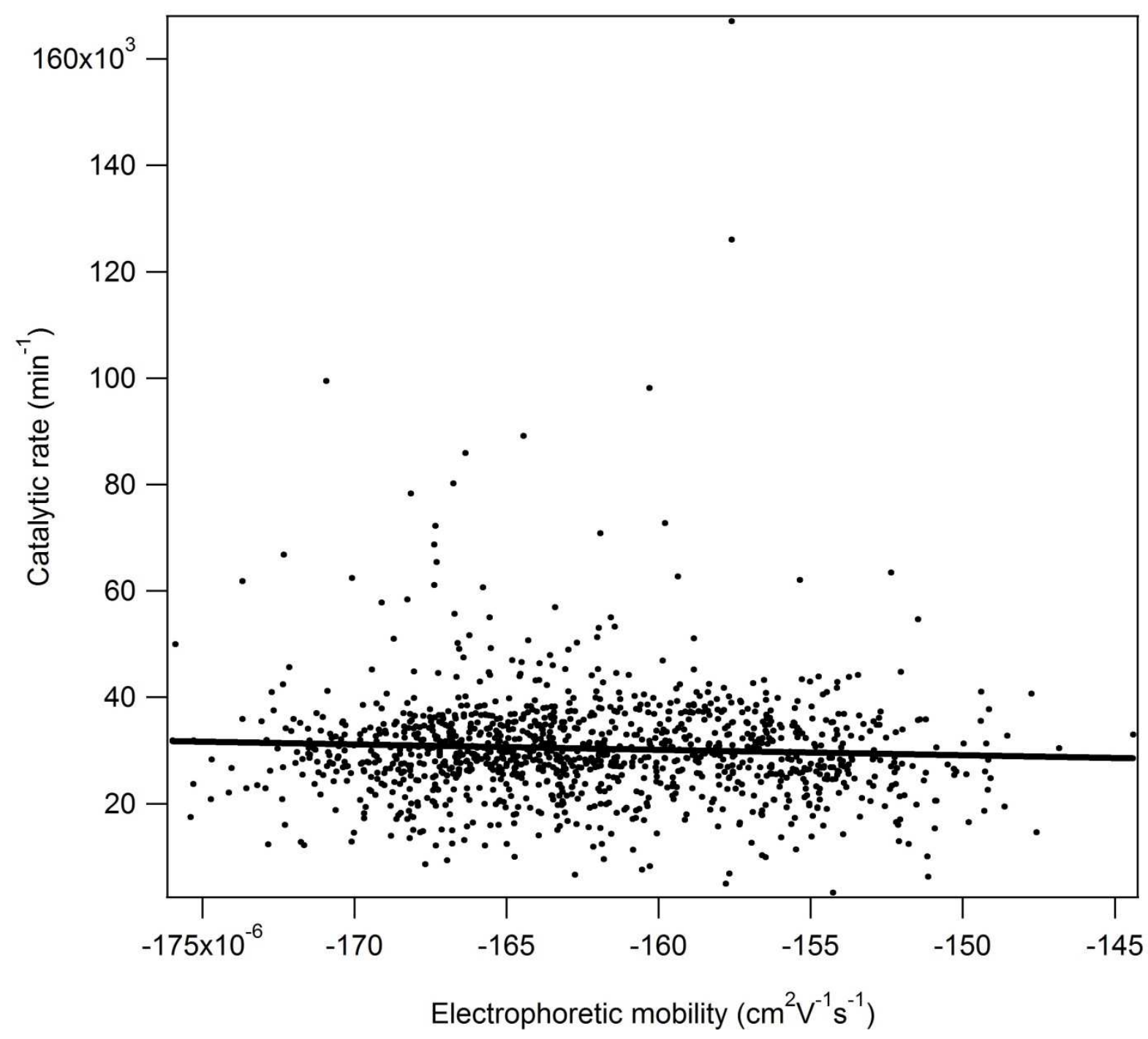




\section{Figure 3}

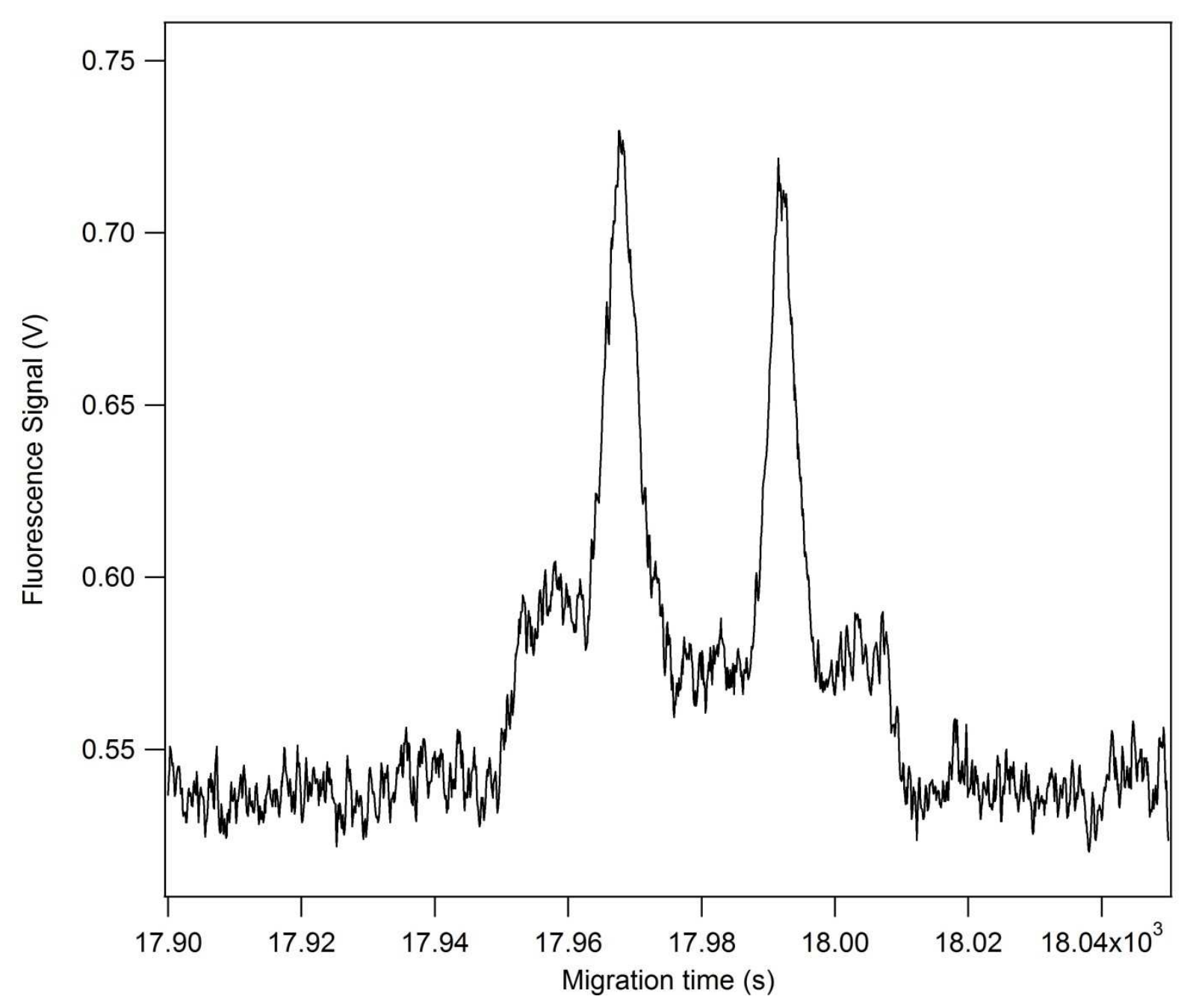




\section{Figure 4}

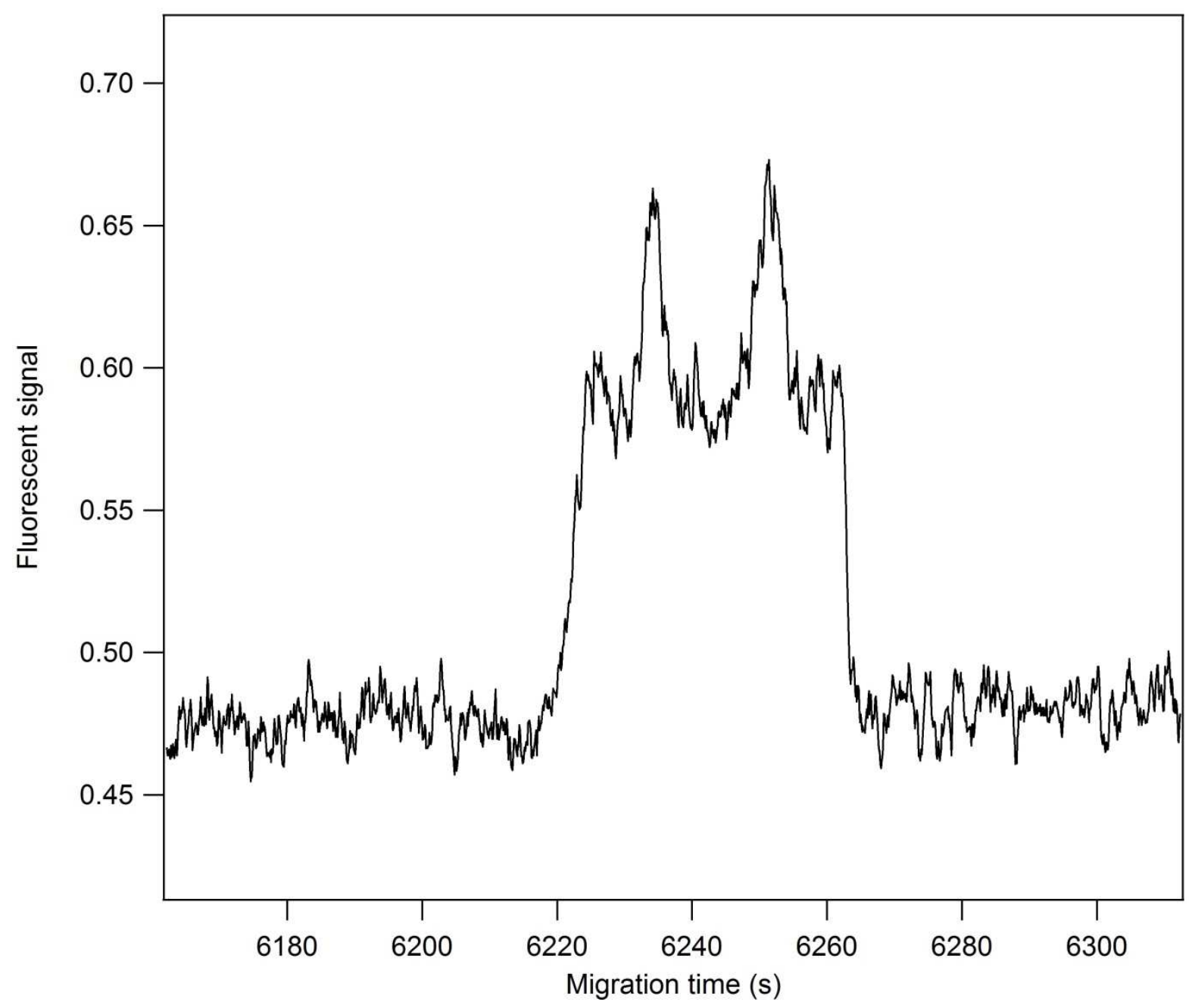




\section{Figure 5}

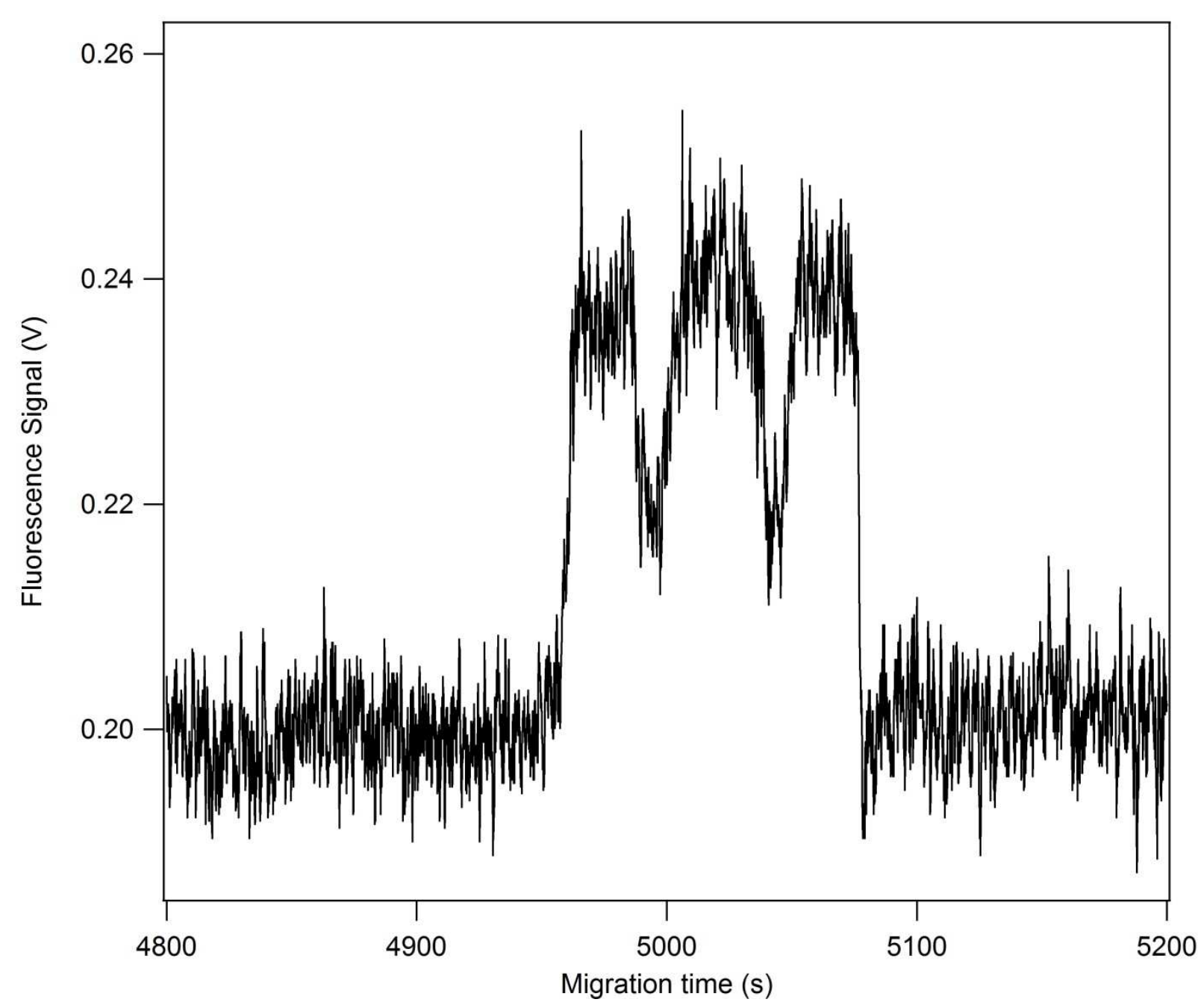


Figure 6

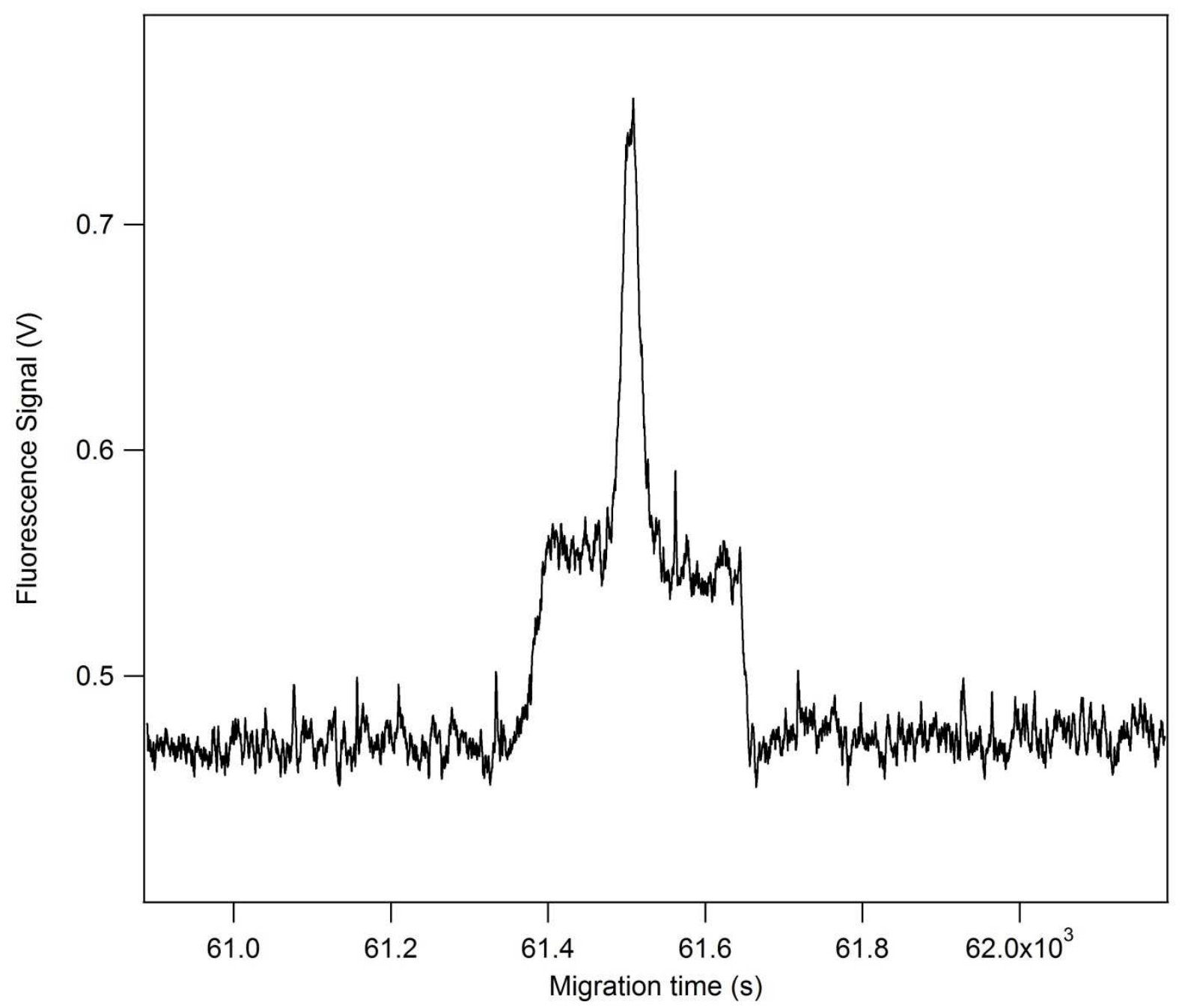




\section{Figure legends}

Figure 1: The resultant electropherogram for the continuous flow assay of E. coli $\beta$ galactosidase is shown. The box-shaped product peaks for 8 individual enzyme molecules are seen. The sample containing enzyme in $50 \mathrm{mM}$ HEPES buffer ( $\mathrm{pH} 7.3$ ) with $1 \mathrm{mM} \mathrm{MgCl}_{2}$ and $50 \mu \mathrm{M}$ DDAO-gal was continuously mobilized through a $40 \mathrm{~cm}$ long, $4.4 \mu \mathrm{m}$ inner diameter capillary at $400 \mathrm{Vcm}^{-1}$ and past a post-column laser-induced fluorescence detector.

Figure 2: The catalytic rate and electrophoretic mobility of 1211 individual $\beta$-galactosidase molecules are shown.

Figure 3: A single $\beta$-galactosidase molecule in 50 mM HEPES (pH 7.3) containing $1 \mathrm{mM}$ $\mathrm{MgCl}_{2}, 1 \mathrm{mM}$ citrate and $50 \mu \mathrm{M}$ DDAO-gal was mobilized through a $60 \mathrm{~cm}$ long, $4.4 \mu \mathrm{m}$ internal diameter capillary at $200 \mathrm{Vcm}^{-1}$ and past a post-column laser-induced fluorescence detector. The initial $15 \mathrm{~cm}$ of the capillary was maintained at $21^{\circ} \mathrm{C}$, the next $5 \mathrm{~cm}$ at $50^{\circ} \mathrm{C}$, the next $20 \mathrm{~cm}$ at $21^{\circ} \mathrm{C}$, the next $5 \mathrm{~cm}$ at $50^{\circ} \mathrm{C}$ and the final $15 \mathrm{~cm}$ at $21^{\circ} \mathrm{C}$. The peak from the resultant electopherogram is shown.

Figure 4: A single $\beta$-galactosidase molecule in 50 mM HEPES (pH 7.3) containing $1 \mathrm{mM}$ $\mathrm{MgCl}_{2}, 1 \mathrm{mM}$ citrate and $50 \mu \mathrm{M}$ DDAO-gal was mobilized through a $60 \mathrm{~cm}$ long, $4.4 \mu \mathrm{m}$ internal diameter capillary at $200 \mathrm{Vcm}^{-1}$ and past a post-column laser-induced fluorescence detector. The initial $15 \mathrm{~cm}$ of the capillary was maintained at $21^{\circ} \mathrm{C}$, the next $5 \mathrm{~cm}$ at $28^{\circ} \mathrm{C}$, the next $20 \mathrm{~cm}$ at $21^{\circ} \mathrm{C}$, the next $5 \mathrm{~cm}$ at $28^{\circ} \mathrm{C}$ and the final $15 \mathrm{~cm}$ at $21^{\circ} \mathrm{C}$. The peak from the resultant electropherogram is shown. 
Figure 5: A single $\beta$-galactosidase molecule in 50 mM HEPES (pH 7.3) containing $1 \mathrm{mM}$ $\mathrm{MgCl}_{2}, 1 \mathrm{mM}$ citrate and $50 \mu \mathrm{M}$ DDAO-gal was mobilized through a $60 \mathrm{~cm}$ long, $4.4 \mu \mathrm{m}$ internal diameter capillary at $200 \mathrm{Vcm}^{-1}$ and past a post-column laser-induced fluorescence detector. The initial $15 \mathrm{~cm}$ of the capillary was maintained at $21^{\circ} \mathrm{C}$, the next $5 \mathrm{~cm}$ at $10^{\circ} \mathrm{C}$, the next $20 \mathrm{~cm}$ at $21^{\circ} \mathrm{C}$, the next $5 \mathrm{~cm}$ at $10^{\circ} \mathrm{C}$ and the final $15 \mathrm{~cm}$ at $21^{\circ} \mathrm{C}$. The peak from the resultant electropherogram is shown.

Figure 6: A single $\beta$-galactosidase in $50 \mathrm{mM}$ HEPES (pH 7.3) containing $1 \mathrm{mM} \mathrm{MgCl}, 1 \mathrm{mM}$ citrate and $50 \mu \mathrm{M}$ DDAO-gal was mobilized through a $60 \mathrm{~cm}$ long, $4.4 \mu \mathrm{m}$ internal diameter capillary at $200 \mathrm{Vcm}^{-1}$ and past a post-column laser-induced fluorescence detector. The initial $27.5 \mathrm{~cm}$ of the capillary was maintained at $21^{\circ} \mathrm{C}$, the next $5 \mathrm{~cm}$ at $50^{\circ} \mathrm{C}$, and the final $27.5 \mathrm{~cm}$ at $21^{\circ} \mathrm{C}$. The peak from the resultant electropherogram is shown. 